\title{
Recent Climate Changes in Hailuogou Watershed on the Eastern Slope of Mount Gongga, South-Eastern Fringe of the Tibetan Plateau, China
}

\author{
Yuchuan Meng1*, Guodong Liu1, Mingxi Li ${ }^{2}$ \\ ${ }^{1}$ State Key Lab. of Hydraulics and Mountain River Eng., College of Water Resource and Hydropower, Sichuan \\ University, Chengdu, Sichuan, China \\ ${ }^{2}$ Department of Hydropower Business, Power China Huadong Engineering Corporation Limited, Hangzhou, \\ Zhejiang, China \\ Email: *mengyuchuan@126.com
}

Received February 2015

\begin{abstract}
Mountainous regions are particularly sensitive to climate change. Seasonal and annual variations in climate already strongly influence the ecosystems in such areas. Temporal and spatial variations of temperature and precipitation, for higher elevation site (Hailuogou Station) and lower elevation site (Moxi Station) within Hailuogou watershed which is located on the eastern slope of Mount Gongga, China, were analyzed to evaluate the extent and trend of climate change. Climate data were carefully checked and corrected for errors before being analyzed. The results of this work indicate that the measured climate data contain a wide magnitude of variations in temperature and precipitation in the mountainous region. The annual, minimal and maximal temperatures exhibit some increasing trends during the studied period. The results of this work show that slightly warming climate is mostly caused by increasing minimum temperature. Maximal precipitation mostly occurs in July and minimal precipitation mostly occurs in December. There exists a slightly declining trend of precipitation during 1988-2009. Precipitation exhibits an increasing trend with altitude, whereas the temperature has the reverse trend in the alpine area during studied period.
\end{abstract}

\section{Keywords}

Temperature, Precipitation, Hailuogou Watershed, Variation, Trend

\section{Introduction}

Earth's mean surface temperature has increased by about $1^{\circ} \mathrm{C}$ since the beginning of the 20th century [1]. Significant climate change is already visible globally, and is expected to become more pronounced in the future [2].

\footnotetext{
${ }^{*}$ Corresponding author.

How to cite this paper: Meng, Y.C., Liu, G.D. and Li, M.X. (2015) Recent Climate Changes in Hailuogou Watershed on the Eastern Slope of Mount Gongga, South-Eastern Fringe of the Tibetan Plateau, China. Journal of Geoscience and Environment Protection, 3, 47-53. http://dx.doi.org/10.4236/gep.2015.32008
} 
Temperature has increased by $0.4^{\circ} \mathrm{C}-0.5^{\circ} \mathrm{C}$ from 1860 to 2005 , especially after 1951 , and the winter temperature rise has shown a larger magnitude, in China [3]. Climate change will lead to wide ranging impacts on the natural and man-made environment across different sectors and regions. Through increases in temperature coupled with changes in precipitation regimes, mountain regions seem to be particularly fragile sensitive to a changing climate [4]. Spatial factors, such as the geographical latitude, influence a region's climate, and mountain ranges mark and regulate regional climate processes [5]. Due to the vertical gradient of the atmospheric parameters, the climate of the mountains differs significantly from the climate of the surrounding plains, basins and valleys. Mountains intensify disparity of climate temporal regimes, and spatial climate contrast from valleys to valleys.

Bordering the Tibetan Plateau, Mount Gongga is located at west of the Sichuan Basin. It is the highest mountain in Sichuan province, and its eastern slopes reach down into the Dadu Valley (1100 m a.s.l.). Many scientific investigations have been undertaken in this region (e.g. [6]-[11]). Located in the eastern slope of Mount Gongga, Hailuogou (HLG) watershed is an ideal location to study the distinctive climate regimes of the alpine region. This paper is aimed a detailed analysis of available meteorological data series and a discussion of the possible climate trends in this mountainous region. Based on the available meteorological data, the spatial and temporal climate change, the overall trend of temperature and precipitation in inter-annual, different season period during 1988-2009, are examined in this work. Analyzing the variations of temperature and precipitation will hopefully lead to a better understanding of climate fluctuations in this mountainous region. We expected that the results will provide an insight for climate, water resource, forestry, and tourism management in alpine regions.

\section{Study Area}

Located in the southeastern edge of the Tibetan Plateau, Mount Gongga $\left(29^{\circ} 20^{\prime}-30^{\circ} 20^{\prime} \mathrm{N}, 101^{\circ} 30^{\prime}-102^{\circ} 15^{\prime} \mathrm{E}\right)$ is the highest peak, $7556 \mathrm{~m}$ a.s.l., in the eastern part of the Tibetan Plateau. As a dividing line in both geography and climate between Sichuan Basin with warm and wet monsoon climate and Tibetan Plateau with cold and dry climate, Mount Gongga belongs to the subtropical mountain climate [12]. HLG watershed is located on the eastern slope of Mount Gongga, ranging from 2756 to $7556 \mathrm{~m}$, with a mean altitude of $4714 \mathrm{~m}$. HLG watershed is characterized by abundant precipitation, small evaporation, large discharge and complex water resource supply in stream flow. Belonging to the wet monsoon climate, the HLG alpine region is controlled by the southwest and southeast monsoons in the summer and by the westerly circulation in the winter.

Two meteorological stations (HLG Station, $3000 \mathrm{~m}$ a.s.l. and Moxi (MX) Station, $1640 \mathrm{~m}$ a.s.l.) were established and maintained by the Gongga Mountain Alpine Ecosystem Station of the Chinese Academy of Sciences in the study region in 1987 (Figure 1). HLG and MX Stations have been put into operation in 1988 and 1992, respectively.

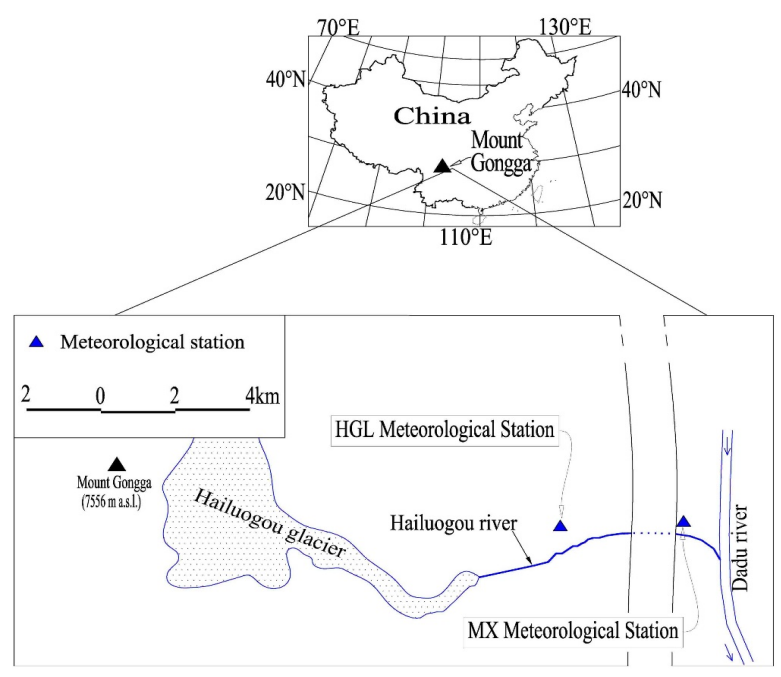

Figure 1. Map of the study watershed, with the two meteorological locations. 


\section{Data and Methods}

The precipitation and temperature data (1988-2009) were provided by the Gongga Mountain Alpine Ecosystem Station, Chengdu Institute of Mountain Hazard and Environment, the Chinese Academy of Sciences. Temperature and precipitation gauge measurements are subject to some range of errors. As continuous and accurate data for climate variables are critical for analyzing the possible climate trends, data quality control is a necessary step before analysis of variation trends of temperature and precipitation.

Twenty-two years (1988-2009) of carefully measured data on temperature and precipitation in HLG watershed are analyzed to evaluate the extent and magnitude of the climate changes. Trends in temperature and precipitation are analyzed by year and season, and computed using least square linear regression method.

\section{Results and Discussion}

\subsection{Temperature}

Figure 2 displays the mean, maximal and minimal data of monthly temperatures and gives overall trends of

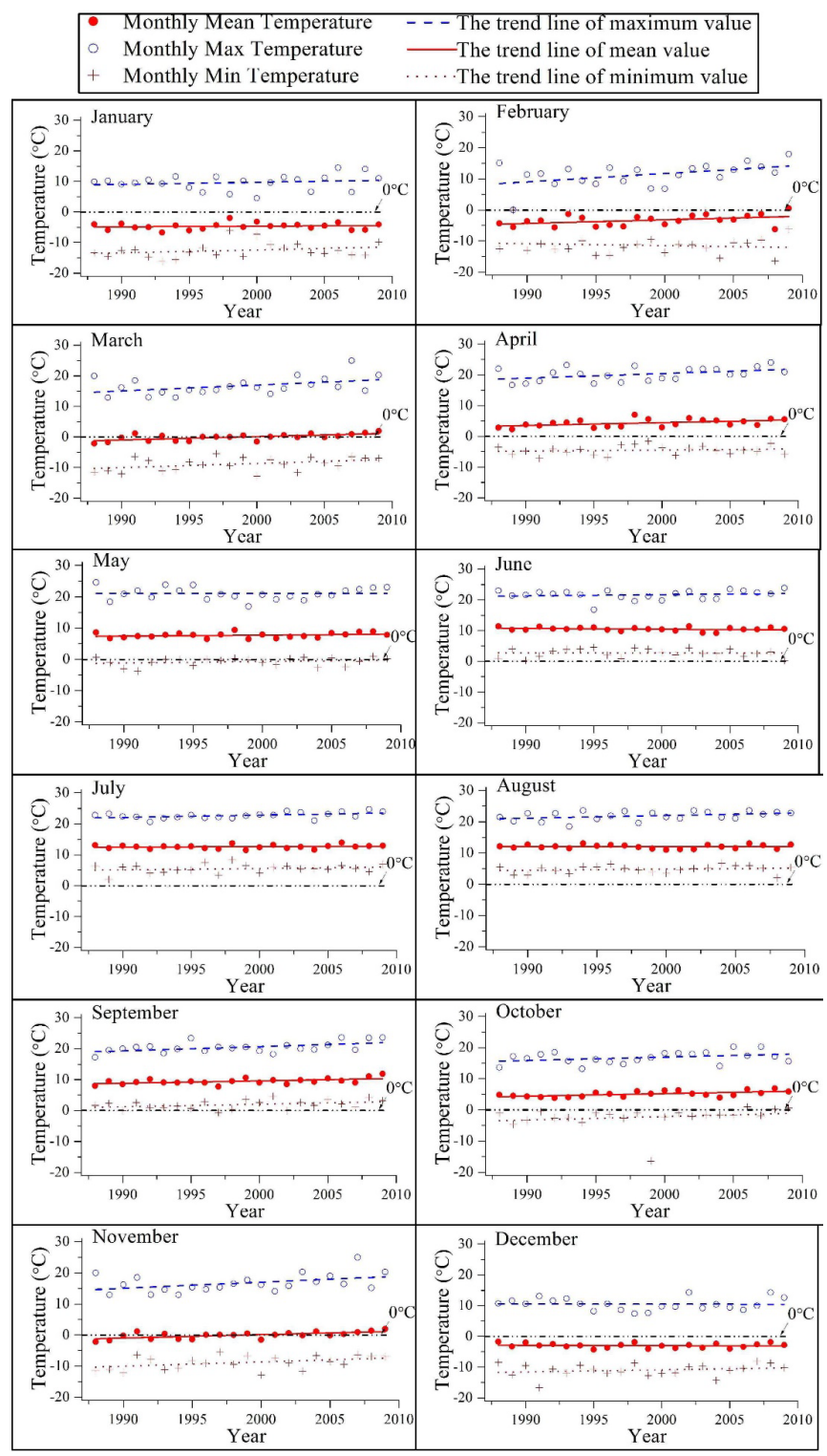

Figure 2. Inter-annual variations of MMeanT, MMinT and MMaxT at HLG Station from 1988 to 2009. 
these data during 1988-2009 at HLG Station. Monthly mean temperature (MMeanT) contains relatively small magnitude of seasonal variations, ranging between $-6.7^{\circ} \mathrm{C}$ and $-2^{\circ} \mathrm{C}$ in January, between $-6.2^{\circ} \mathrm{C}$ and $0.52^{\circ} \mathrm{C}$ in February, between $-2.1^{\circ} \mathrm{C}$ and 1.9519 in march, between $2.3^{\circ} \mathrm{C}$ and $7^{\circ} \mathrm{C}$ in April, between $6.5^{\circ} \mathrm{C}$ and $9.4^{\circ} \mathrm{C}$ in May, between $9.2^{\circ} \mathrm{C}$ and $11.4^{\circ} \mathrm{C}$ in June, between $11.5^{\circ} \mathrm{C}$ and $13.9^{\circ} \mathrm{C}$ in July, between $11^{\circ} \mathrm{C}$ and $13.1^{\circ} \mathrm{C}$ in $\mathrm{Au}-$ gust, between $7.7^{\circ} \mathrm{C}$ and $11.8^{\circ} \mathrm{C}$ in September, between $3.8^{\circ} \mathrm{C}$ and $6.9^{\circ} \mathrm{C}$ in October, between $2.3^{\circ} \mathrm{C}$ and $7{ }^{\circ} \mathrm{C}$ in November, and between $-4.3^{\circ} \mathrm{C}$ and $-1.7^{\circ} \mathrm{C}$ in December, respectively, in HLG Station from 1988 to 2009 . The highest value of MMeanT data was observed in January 1993 , with its value around $-6.7^{\circ} \mathrm{C}$, whereas the lowest value was observed in July 2006 , with its value around $13.9^{\circ} \mathrm{C}$. The twelve monthly data records of MMeanT at HLG Station have a similar pattern of variability but a slight difference in the amplitude of variations. Based on the result from seasonal temperature variations at HLG Station, MMeanT data overall exhibits slightly increasing trends during the study period. The increasing trend is more remarkable in February from 1988 to 2009.

There is a similar pattern of increasing trend in MMeanT, monthly maximal temperature (MMaxT) and monthly minimal temperature (MMinT). The results of this study show that the MMaxT and MMinT contain a relatively wide range of variations in temperature values.

Figure 3 shows temporal changes in annual mean temperature (AMeanT), annual maximal temperature (AMaxT) and annual minimal temperature (AMinT) at HLG Station during the investigated period. Their average values of AMeanT, AMaxT and $\mathrm{AMinT}$ are $4.32^{\circ} \mathrm{C}, 23.45^{\circ} \mathrm{C},-13.91^{\circ} \mathrm{C}$, respectively. Between 1988 and 2009, the temperature values of AMeanT and AMaxT are both above $0^{\circ} \mathrm{C}$, but those of AMinT are well below $0^{\circ} \mathrm{C}$. A trend toward temperature increase in HLG watershed can be verified when looking at the annual temperature time series (Figure 3). It would tend to indicate an evolution in the annual temperature regime for period 1988-2009. Especially the increasing trend of AMinT is more obvious than that of AMaxT, indicating that an annual temperature increase is mostly caused by a larger increasing magnitude of AMinT in HLG watershed.

To analyze the altitude effect of temperature in HLG watershed, the temperature data measured at HLG station is compared with that at MX station in 2009. It is well known that the values of temperature vary according to altitude in mountainous regions. Figure 4 displays the mean monthly temperatures of the selected two meteorological stations and gives an overview of the regional temperature range and the spread of MMeanT. It is to notice that the values of MMeanT, measured in both stations, are above $0^{\circ} \mathrm{C}$ except for the two values of MMeanT at HLG Station in January 2009 and December 2009. January is the coldest month and July is the warmest month in HLG watershed. It is evident that the values of MMeanT and AMeanT at MX station are larger than those of HLG station (Figure 5), indicating that the decrease of temperature with altitude is well developed in this alpine region. The results of temperature measurements show a considerably large magnitude of differences, between the higher station (HLG station) and the lower station (MX station), ranging from $7.46^{\circ} \mathrm{C}$ in

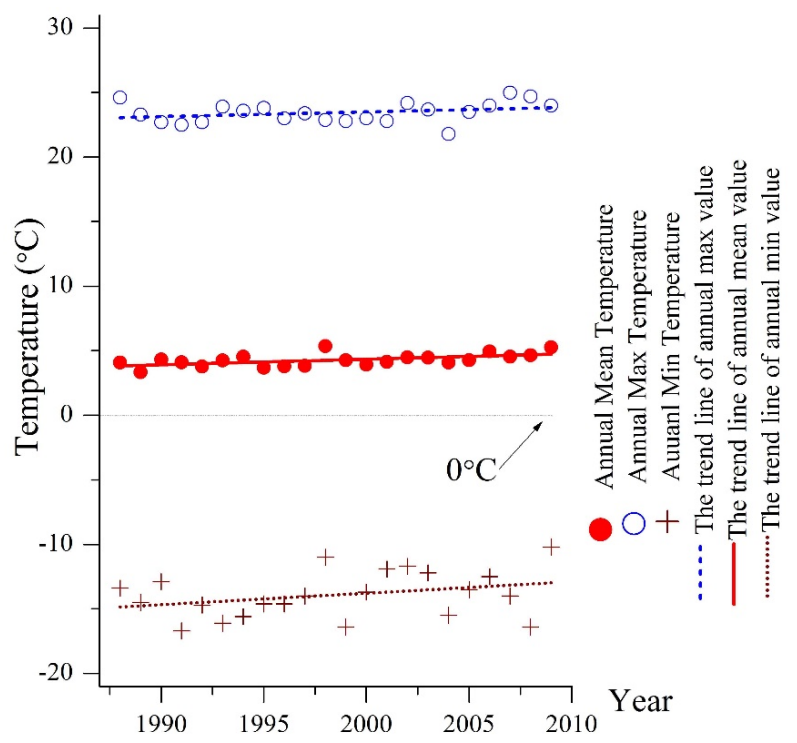

Figure 3. Inter-annual variations of annual mean, maximal and minimal temperatures at HLG Station from 1988 to 2009. 
September to $8.98^{\circ} \mathrm{C}$ in February. Both MMaxT and MMinT overall increase in summer and decrease in winter, similar to the pattern of MMeanT variations in the mountainous watershed.

At the higher region (HLG station, 2009), the average daily temperature ranged from $-10.2^{\circ} \mathrm{C}$ in December 28 to $24^{\circ} \mathrm{C}$ in July 21 , with an annual average of $5.26^{\circ} \mathrm{C}$, but at the lower region (MX station, 2009), the average daily temperature ranged from $-1.6^{\circ} \mathrm{C}$ in November 21 to $32.7^{\circ} \mathrm{C}$ in July 19 , with an annual average of $13.31^{\circ} \mathrm{C}$ (Figure 5). This clearly implies the influence of altitude over temperature changes in the mountainous region.

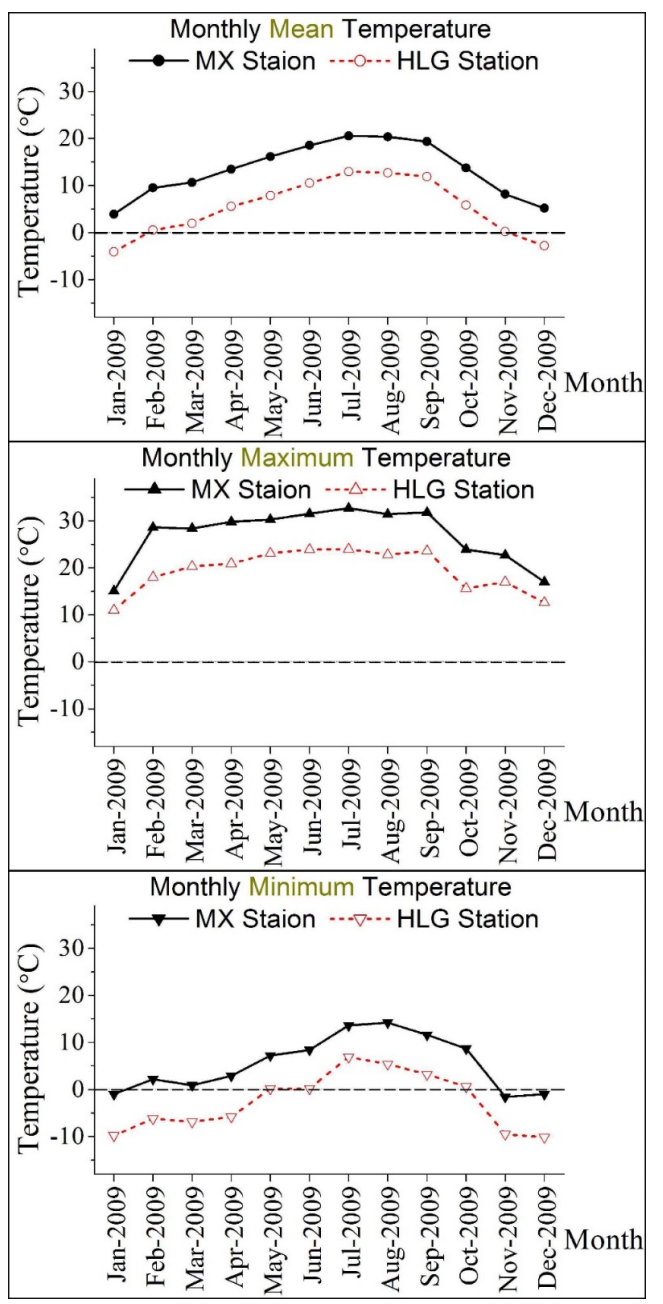

Figure 4. Intra-annual variations of monthly values of temperature at HLG Station and MX Station in 2009.

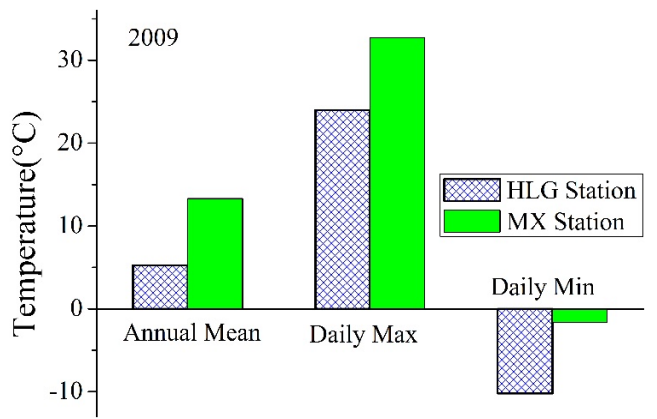

Figure 5. Intra-annual variations of monthly values of temperature at HLG Station and MX Station in 2009. 


\subsection{Precipitation}

Figure 6 displays inter-annual changes of monthly precipitation and annual precipitation during 1988-2009 at HLG Station. Monthly precipitation contains a relatively wide range of variations during the investigated period. These twelve monthly precipitations have a similar pattern of variability but a slight distinction in the range of variations.

Maximum monthly precipitation occurs in July, ranging from $171.3 \mathrm{~mm}$ to $379.6 \mathrm{~mm}$, and minimal precipitation occurs in December, ranging from $10 \mathrm{~mm}$ to $53.4 \mathrm{~mm}$. The annual precipitation contains a large magnitude of variations, ranging from $1250.9 \mathrm{~mm}$ in 2009 to $2175.4 \mathrm{~mm}$ in 1997 . When looking at annual precipitation data, a slightly declining trend can be detected during the study period.

The altitude distribution patterns of annual precipitation and average monthly precipitation are shown in Figure 7. There is a similar pattern of temporal variations in monthly precipitation in MX Station and HLG Station. At the higher region (HLG station, 2009), the average daily temperature ranged from $-10.2^{\circ} \mathrm{C}$ in December 28 to $24^{\circ} \mathrm{C}$ in July 21 , with an annual average of $5.26^{\circ} \mathrm{C}$, but at the lower region (MX station, 2009), the average daily temperature ranged from $-1.6^{\circ} \mathrm{C}$ in November 21 to $32.7^{\circ} \mathrm{C}$ in July 19 , with an annual average of $13.31^{\circ} \mathrm{C}$. The monthly and annual precipitations at the higher mountainous region are generally larger than those at the lower mountainous region. This is interpreted to indicate that, as a whole, the regional trend in precipitation exhibits an increasing trend with altitude, whereas the temperature has the reverse trend in the study mountainous region.

\section{Conclusions}

Situated on the eastern slope of Mount Gongga, HLG watershed belongs to the wet monsoon climate of the sub-

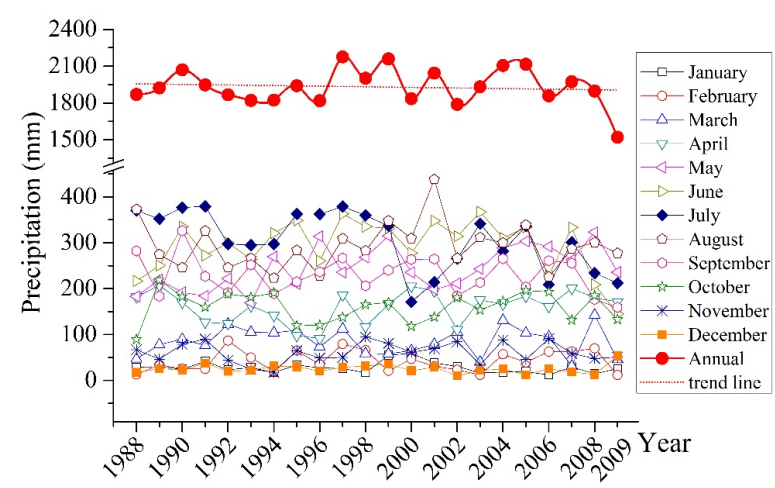

Figure 6. Inter-annual variations of monthly and annual precipitations in HLG Station from 1988 to 2009.

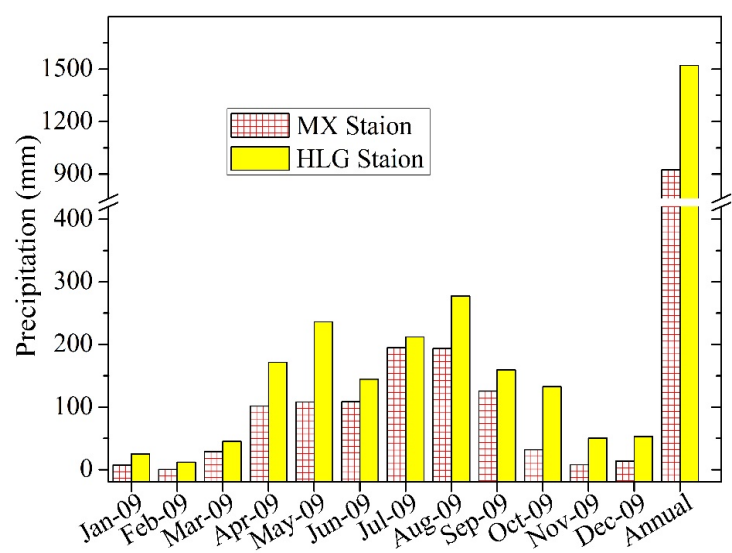

Figure 7. The monthly and annual data of precipitation measured at HLG Station and MX Station in 2009. 
tropical mountain. On the basis of the climate data (at $3000 \mathrm{~m}$ a.s.1.) from 1988 to 2009, there exists a wide range of temporal variations in temperature and precipitation in the mountainous region. There is a similar pattern of increasing trend in MMeanT, MMaxT and MMinT. A trend toward temperature increase can be verified when analyzing the temperature time series. During 1988-2009, the regional climate warmed slightly, that is mostly caused by increasing minimum temperature. Temperature at HLG station is mostly higher than that in MX station, indicating the decrease of temperature with altitude in the mountainous region.

Precipitation contains a relatively wide range of temporal variations in HLG watershed. Most of the time, maximal precipitation occurs in July and minimal precipitation occurs in December. The annual precipitation contains a large magnitude of temporal variations and a slightly declining trend can be detected, during 1988-2009. Precipitation at HGL station is larger than that at MX station, indicating that precipitation exhibits an increasing trend with altitude, whereas the temperature has the reverse trend in the study area.

\section{Acknowledgements}

This study was supported by Youth Foundation of Sichuan University (Grant No. 2015SCU11048) and the Key Projects of Natural Science Foundation of China (Grant No. 40730634). The authors are grateful to the Gongga Mountain Alpine Ecosystem Station, Chengdu Institute of Mountain Hazard and Environment, the Chinese Academy of Sciences, Sichuan, China, for supplying necessary meteorological data.

\section{References}

[1] Salama, M.S., Van der Velde, R., Zhong, L., Ma, Y., Ofwono, M. and Su, Z. (2012) Decadal Variations of Land Surface Temperature Anomalies Observed over the Tibetan Plateau by the Special Sensor Microwave Imager (SSM/I) from 1987 to 2008. Climatic Change, 114, 769-781. http://dx.doi.org/10.1007/s10584-012-0427-3

[2] Deng, M.Z., Qin, D.H. and Zhang, H.G. (2012) Public Perceptions of Climate and Cryosphere Change in Typical Arid Inland River Areas of China: Facts, Impacts and Selections of Adaptation Measures. Quaternary International, 282, 48-57. http://dx.doi.org/10.1016/i.quaint.2012.04.033

[3] Li, Z.X., He, Y.Q., Wang, C.F., Wang, X.F., Xin, H.J., Zhang, W. and Cao, W.H. (2011) Spatial and Temporal Trends of Temperature and Precipitation during 1960-2008 at the Hengduan Mountains, China. Quaternary International, 236, 127-142. http://dx.doi.org/10.1016/j.quaint.2010.05.017

[4] McDowell, G., Stephenson, E. and Ford, J. (2014) Adaptation to Climate Change in Glaciated Mountain Regions. Climatic Change, 126, 77-91. http://dx.doi.org/10.1007/s10584-014-1215-Z

[5] Grunewald, K., Scheithauer, J., Monget, J.M. and Brown, D. (2009) Characterisation of Contemporary Local Climate Change in the Mountains of Southwest Bulgaria. Climatic Change, 95, 535-549. http://dx.doi.org/10.1007/s10584-008-9508-8

[6] Zheng, B.X. and Ma, Q.H. (1994) The Glaciers Variation, Climate Change and the Rover Valley Development in the Holocene on the Gongga Mountain. Acta Geographica Sinica, 49, 500-508.

[7] Owen, L.A., Finkel, R.C., Barnard, P.L., Ma, H.Z., Asahi, K., Caffee, M.W. and Derbyshire, E. (2005) Climatic and Topographic Controls on the Style and Timing of Late Quaternary Glaciation throughout Tibet and the Himalaya Defined by Be-10 Cosmogenic Radionuclide Surface Exposure Dating. Quaternary Science Reviews, 24, 1391-1411. http://dx.doi.org/10.1016/j.quascirev.2004.10.014

[8] Yin, G., Wang, X.D., Gao, Z.Y., Yan, Q.S. and Huang, Y. (2008) Study of the Hydrology of Glacial Runoff in Hailuogou Valley, Gongga Mountain by Means of Isotopic Tracing. Journal of Glaciology and Geocryology, 30, 365-372.

[9] Li, Z.X., He, Y.Q., Yang, X.M., Theakstone, W.H., Jia, W.X., Pu, T., et al. (2010). Changes of the Hailuogou Glacier, Mt. Gongga, China, against the Background of Climate Change during the Holocene. Quaternary International, 218, 166-175. http://dx.doi.org/10.1016/j.quaint.2008.09.005

[10] Wang, J., Pan, B.T., Zhang, G.L., Cui, H., Cao, B. and Geng, H.P. (2013) Late Quaternary Glacial Chronology on the Eastern Slope of Gongga Mountain, Eastern Tibetan Plateau, China. Science China-Earth Sciences, 56, 354-365. http://dx.doi.org/10.1007/s11430-012-4514-0

[11] Meng, Y.C., Liu, G.D. and Zhang, L.T. (2014) A Comparative Study on Stable Isotopic Composition in Waters of the Glacial and Nonglacial Rivers in Mount Gongga, China. Water and Environment Journal, 28, 212-221. http://dx.doi.org/10.1111/wej.12027

[12] Meng, Y.C. and Liu, G.D. (2013) Stable Isotopic Information for Hydrological Investigation in Hailuogou Watershed on the Eastern Slope of Mount Gongga, China. Environmental Earth Sciences, 69, 29-39. http://dx.doi.org/10.1007/s12665-012-1931-5 